Family Profile No. 28

\title{
Stepfamilies in First Marriages
}

Author: Lisa Carlson

Stepfamilies are created when the formation of a new union involves at least one partner who has child(ren) from a prior relationship. Although most stepfamilies occur through remarriage, some stepfamilies are formed in first marriages due to nonmarital childbearing (FP-16-09). The proportion of children living in stepfamilies has been steady since the 1990s (FP-17-16; FP-19-25), at about 9\%. About half of these children reside in married stepfamilies and half are in cohabiting stepfamilies (FP-1925). Using the 2015-2019 cycles of the National Survey of Family Growth, this family profile examines the share of individuals entering a first marriage with at least one stepchild (regardless of that child's living arrangements) among men and women who married within the five years preceding the survey. We also examine the share of first marriages resulting in the formation of a stepfamily by gender, education, race/ethnicity, and age at marriage.

\section{Share of Stepfamilies at First Marriage}

- Among men and women who recently entered a first marriage, the majority ( $85 \%$ ) had no residential or nonresidential stepchildren.

- The share of women who recently married for the first time and entered a stepfamily was slightly larger than the share for men ( $16 \%$ compared to $14 \%$, not shown).

Figure 1. Stepfamily Status at First Marriage Among Marriages Occurring Within the Five Years Prior to the Survey

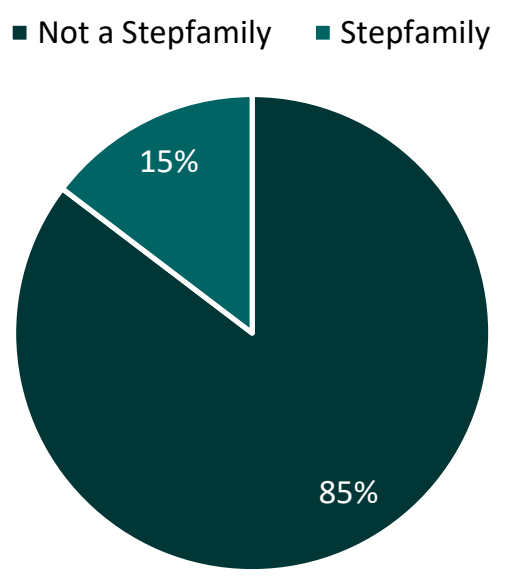

Source: NCFMR analyses of NSFG 2015-2017 and 2017-2019 female and male data files

\section{Educational Attainment}

Figure 2: Stepfamily Status at First Marriage by Educational Attainment Among Marriages Occurring Within the Five Years Prior to the Survey

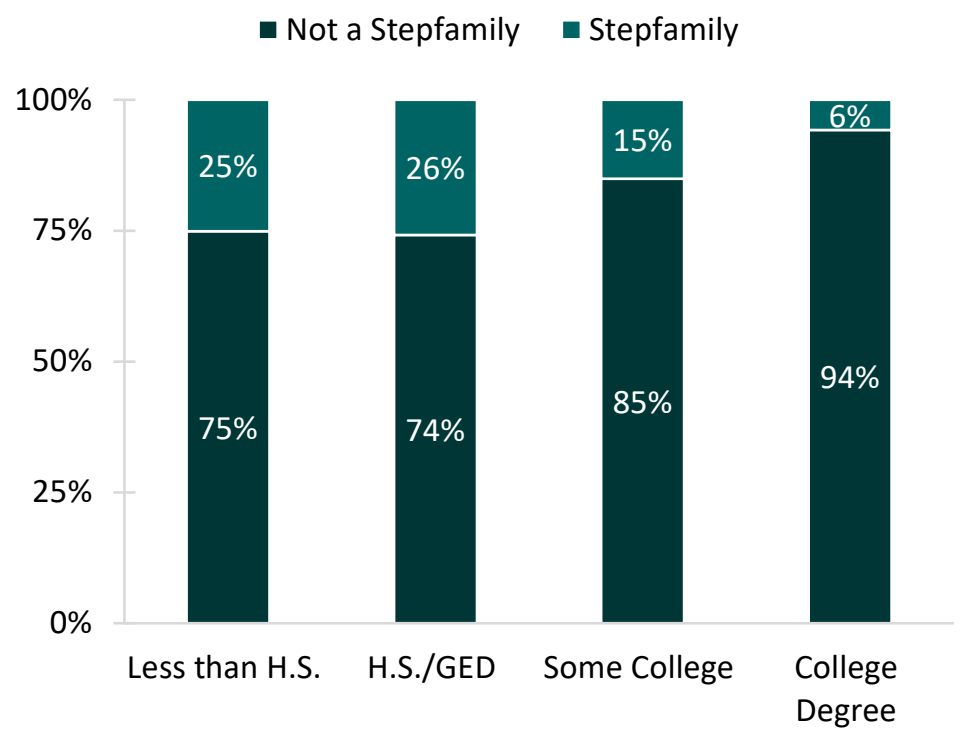

Source: NCFMR analyses of NSFG 2015-2017 and 2017-2019 female and male data files
- The share of men and women who recently entered a stepfamily via first marriage was similar for those with a high school diploma or less but declined with higher levels of education.

- Compared to those with a college degree, it was at least twice as common for all other educational groups to have any stepchildren at first marriage.

- The share of men and women in their first marriage with at least one residential or nonresidential stepchild was highest among those with a high school diploma (26\%). 


\section{Race \& Ethnicity}

- The proportion of men and women who had any stepchildren at first marriage varied by race and ethnicity.

- The share entering a stepfamily via a first marriage was highest among Black adults (28\%), while the shares for White, Other, and Hispanic adults were at or slightly below $15 \%(13 \%, 14 \%$, and $15 \%$ respectively).

Figure 3: Stepfamily Status at First Marriage by Race/Ethnicity Among Marriages Occurring Within the Five Years Prior to the Survey

$$
\text { - Not a Stepfamily } \quad \text { Stepfamily }
$$

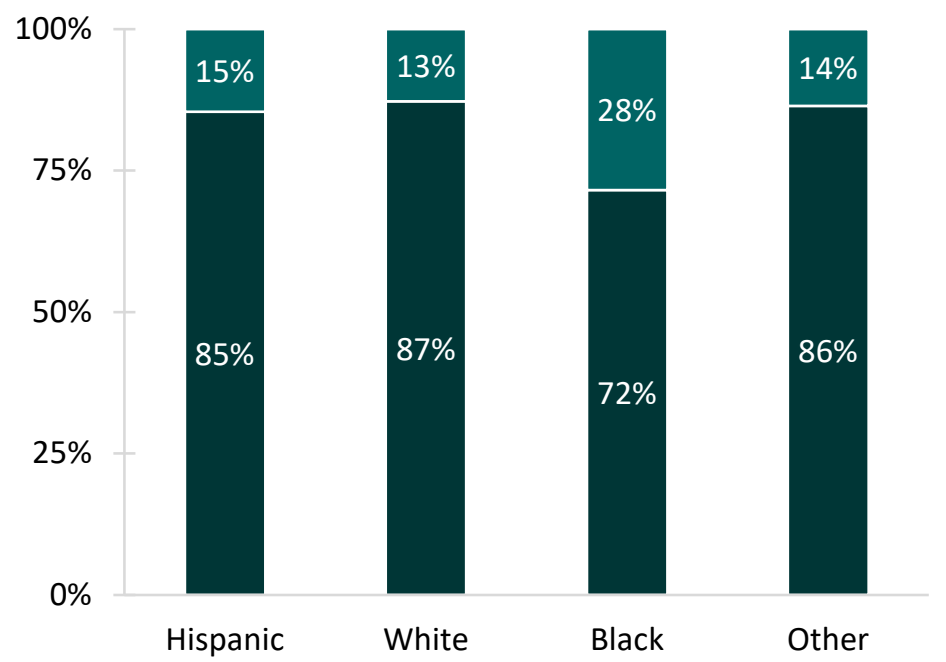

\section{Age Group}

- For men and women, the proportion with any stepchildren when they entered their first marriage increased with age.

- About a quarter of men and women who entered their first marriage at age 30 or older were in a stepfamily. In comparison, around 1 in 10 men and women who entered their first marriage before age 30 were in a stepfamily ( $8 \%$ if under $24,12 \%$ if between $25-29$ ).

Figure 4: Stepfamily Status at First Marriage by Age Among Marriages Occurring Within the Five Years Prior to the Survey

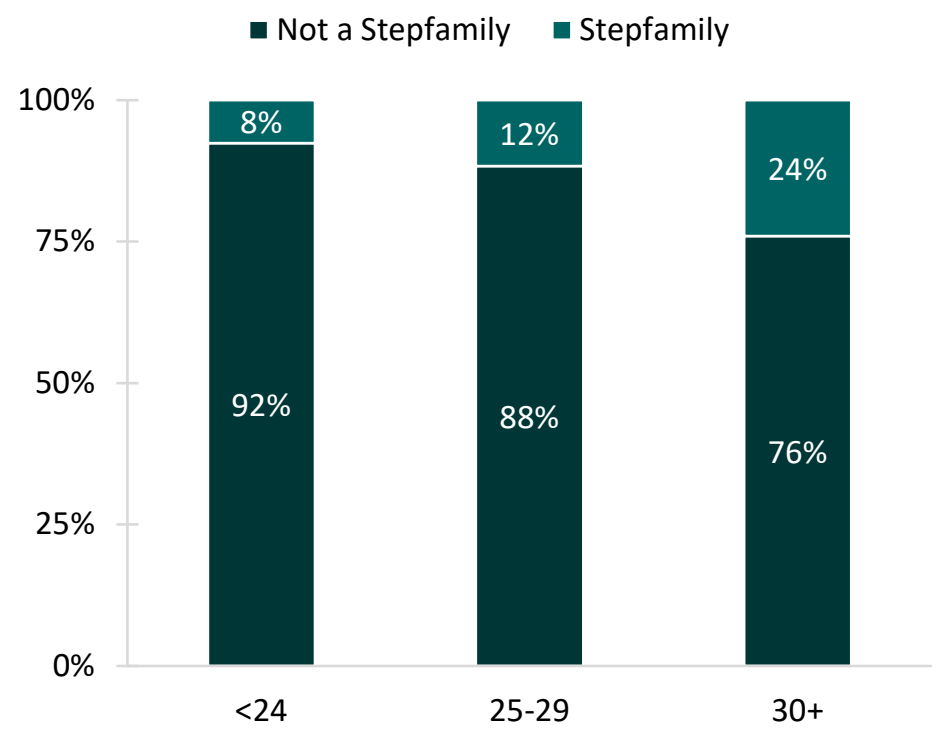

Source: NCFMR analyses of NSFG 2015-2017 and 2017-2019 female and male data files

\section{References:}

Eickmeyer, K. J. (2017). American children's family structure: Stepparent families. Family Profiles, FP-17-16. Bowling Green, OH: National Center for Family \& Marriage Research. https://doi.org/10.25035/ncfmr/fp-17-16

Guzzo, K. B. (2016). Stepfamilies in the U.S. Family Profiles, FP-16-09. Bowling Green, OH: National Center for Family \& Marriage Research. https://www.bgsu.edu/content/dam/BGSU/college-of-arts-and-sciences/NCFMR/documents/FP/guzzostepfamilies-women-fp-16-09.pdf

Payne K. K. (2019). Children's family structure, 2019. Family Profiles, FP-19-25. Bowling Green, OH: National Center for Family \& Marriage Research. https://doi.org/10.25035/ncfmr/fp-19-25.

\section{Suggested Citation:}

Carlson, L. (2020). Stepfamilies in First Marriages. Family Profiles, FP-20-28. Bowling Green, OH: National Center for Family \& Marriage Research. https://doi.org/10.25035/ncfmr/fp-20-28

B O W L I N G G R E E N S T A T E U N I V E R s I T Y
This project is supported with assistance from Bowling Green State University. From 2007 to 2013, support was
the U.S. Department of Health and Human Services, Office of the Assistant Secretary for Planning and Evaluation. The opinions and conclusions expressed herein are solely those
of the author(s) and should not be construed as representing the opinions or policy of any agency of the state or federal government.

